\title{
Thermal Convection Mechanics
}

\section{Kern E. Kenyon}

4632 North Lane, Del Mar, USA

Correspondence to: Kern E. Kenyon, kernken@aol.com

Keywords: High Pressure, Thermal Convection, North Pacific

Received: July 8, 2020 Accepted: September 12, $2020 \quad$ Published: September 15, 2020

Copyright $\odot 2020$ by author(s) and Scientific Research Publishing Inc.

This work is licensed under the Creative Commons Attribution International License (CC BY 4.0).

http://creativecommons.org/licenses/by/4.0/

\section{(c) (i) Open Access}

\section{ABSTRACT}

Assuming thermal convection takes place continuously inside the North Pacific High, an application of physics to the rising sea-warmed air plumes increases understanding of the relatively high air pressure at the sea surface and at the bases of the plumes. Since the ocean is warmer than the air under the NPH, heat is transferred upward decreasing the air density, which should then accelerate upward when no other forces are around to stop it. By Newton's $3^{\text {rd }}$ law the upward accelerating air will cause an equal but opposite (downward) reaction resulting in high pressure in the air under the rising column. That is the central proposal offered, which is consistent with available observations. New data that confirm the upward acceleration of the heated air are especially needed. Perhaps dye or neutrally buoyant particles could be released from a ship or buoy to make the upward air motion visible.

\section{INTRODUCTION}

Thermal convection has recently partly explained the existence and the seasonal variation of the North Pacific High Pressure Cell (NPH) off the coast of California [1]. Available observational evidence consistent with this idea has been presented, which show how the return flow down to the sea surface, from some altitude that is not yet exactly known, can lead to higher pressure there. Here is given a physical explanation of how the rising plume of sea-warmed air itself can produce relatively high air pressure at and very near the sea surface. Therefore, a more complete understanding of the NPH is obtained for the whole sea surface area underneath it.

Thermal convection requires that the sea be warmer than the air so that the air is heated from below. That source of heat is provided by a permanent wide $(4000 \mathrm{~km}$ along $35 \mathrm{~N}$ ) warm surface current that flows northeast off California from tropical latitudes into the Gulf of Alaska and it goes under the NPH [2]. Below the discussion adds to the existing explanation for such a striking relation between atmosphere and ocean.

\section{METHOD}

Consider a large area of warm ocean surface water underlying an equal area of cooler atmospheric air. 
To be specific "large" could mean $4000 \mathrm{~km}$ in cross-section. Any horizontal motions of either air or water are not important for the present so they are assumed to be zero. Due to the given temperature difference, which is taken to be maintained, the ocean will heat the atmosphere from below causing thermal convection to take place. Heat is then advected vertically upward in the mean. Details of the structure of the convection are not known at this point. A few physical ideas are presented that might increase understanding of the convection circulation.

It is conceivable that each rising plume of warmed air could take heat away from the ocean at exactly the same rate as it is imparted to the air in contact with it. Otherwise pulsations, time variations, would occur which are either regular or more likely irregular.

Air has the equation of state, the perfect gas law [3]

$$
p=R \rho T
$$

where $p$ is the pressure, $p$ is the density, $T$ is the temperature and $R$ is a constant. Equation (1) applies to a fluid but is independent of any motion of the air.

Let a sizeable piece of air, small by comparison to the whole warm ocean area, and a thickness that is initially small, be heated from below by the warmer ocean. Its temperature will increase and it will expand, mainly upward. The density of this piece will decrease according to (1) because the pressure will not be able to change much at all since the air is not confined inside a container with rigid sides or a rigid lid, for example. This piece of air is then hydrostatically unstable and will attempt to rise vertically. In fact, it will accelerate vertically against gravity unless prevented from doing so by some other force. Equation (1) does not predict acceleration per say; it predicts a change in density from which acceleration is inferred.

From (1) comes another deduction

$$
\frac{\Delta \rho}{\rho} \approx \frac{\Delta T}{T} \ll 1
$$

where $\Delta \rho=\rho-\rho^{\prime}$ and $\rho$ is the ambient density, outside the rising plume of density $\rho^{\prime}$. Evaluating the RHS of (2) using data from an oceanographic cruise gives

$$
\Delta T / T \approx 2 / 300
$$

Because over the region of the $4000 \mathrm{~km}$ warm current off California it has been found that the sea surface was always warmer than the air and by an average of $2 \mathrm{C}$ in March/April of 1976 along $35 \mathrm{~N}$ [2]. In other words, the upward acceleration of the sea-warmed air is very small, compared to the downward acceleration of gravity (see Equation (4)).

In rising upward as a continuous body of warmed air Bernoulli's law can be applied to the streamlines, but a term needs to be added to the classical form of the equation to account for the upward acceleration against gravity [4]

$$
p=\text { const }-\frac{1}{2} \rho V^{2}+\left(\rho-\rho^{\prime}\right) g z
$$

where $V$ is the vertical speed, $g$ is the acceleration of gravity and $z$ measures altitude above sea level. Equation (4) is not a standard form of Bernoulli's law because of the last term of the RHS, which to my knowledge has only appeared once before in print [4].

Near the sea surface the vertical velocity along a streamline of a rising plume of warmed air is very small so the pressure change there is due to the last term on the RHS of (4), the upward acceleration, and it is a positive change: where the acceleration is greatest the pressure is also greatest. Usually Bernoulli's law says that where the speed is greatest the pressure is least. But now Newton's third law, action equals reaction, has come in to dominate the situation. Including Newton's third law in evaluating a fluid dynamic problem is a very rare occurrence [5].

\section{DISCUSSION}

To see if the physical reasoning contained in Equation (4) is consistent with observations, one exam- 
ple is provided. Ignore the velocity term on the RHS and figure out how the acceleration term could produce a pressure variation similar to what the data show. Typical of winter conditions is a monthly mean sea level pressure chart for the whole North Pacific and the month of January, 1955 [6]. At the center of the NPH the pressure is about $50 \mathrm{mb}$ above ambient values. Converting to the cgs system that is $5 \times 10^{4}$ dynes per $\mathrm{cm}^{2}$. Assume that the upward acceleration of the warmed air in the rising plume is constant up to an altitude of $z$. From the last term of Equation (4) that elevation turns out to be $75 \mathrm{~m}$ to produce the given increased pressure, when Newton's third law is applied and the numerical density ratio in (3) is used. Although $75 \mathrm{~m}$ is not an unreasonable value, there is nothing to compare it to. More work needs to be done to fill that gap in.

Building up the model further is one possibility for the future. For example, an upward accelerating warmed stream of air would become narrower in horizontal cross-sectional area with increasing altitude, and using conservation of mass then produces an additional equation coupling two of the variables, vertical speed and acceleration.

Along with model building new observations would be very valuable for not only proving that thermal convection occurs inside the North pacific High but also obtaining a clear picture of what the convection cells looks like.

Another type of confirmation of the concept of thermal convection, involving sea warmed air in rising plumes, causing the North Pacific High, is in the summer months when the NPH swells in size westward [2] and occasionally forms a second high to the west [7]. There is in those months over at least a 30 year span a second source of heat for the atmosphere: a very wide northward surge of warm surface water $[8]$.

\section{CONCLUSION}

The permanent wide warm surface current flows northeast off the coast of California, and the North Pacific High (NPH) sits on top of it most of the time. It is assumed that heat is transferred from the warm water to the air by thermal convection involving plumes of rising air that accelerate upward. At the bases of these plumes relatively high pressure is caused by a reaction downward to the upward acceleration by Newton's third law. That is the conclusion supported by available data. More data are needed for confirmation of the upward moving air.

\section{ACKNOWLEDGEMENTS}

Comments by the Reviewer increased the clarity and some of the content of the text.

\section{CONFLICTS OF INTEREST}

The author declares no conflicts of interest regarding the publication of this paper.

\section{REFERENCES}

1. Kenyon, K.E. (2020) Thermal Convection in the North Pacific High Pressure Cell. Natural Science, 12, 516-519. https://doi.org/10.4236/ns.2020.127040

2. Kenyon, K.E. (1999) North Pacific High: An Hypothesis. Atmospheric Research, 51, 15-34. https://doi.org/10.1016/S0169-8095(98)00110-0

3. Brunt, D. (1952) Physical and Dynamical Meteorology. Cambridge University Press, London, 30.

4. Kenyon, K.E. (2015) Bernoulli's Equation with Acceleration. Natural Science, 7, 488-490. https://doi.org/10.4236/ns.2015.710050

5. Kenyon, K.E. (2006) Reaction Forces of Fluid Flows on Solid Boundaries. Physics Essays, 19, 507-516. https://doi.org/10.4006/1.3028856 
6. Fofonoff, N.P. (1960) Transport Computations for the North Pacific, 1955. Fisheries Research Board of Canada, Manuscript Report Series No. 77.

7. Kenyon, K.E. (2016) Double North Pacific High in Summer. Natural Science, 8.

8. Kenyon, K.E. (2018) North Pacific Very Wide Warm Surface Flow in Summer. Natural Science, 10, 313-317. https://doi.org/10.4236/ns.2018.108031 